\title{
Attention Drives Synchronization of Alpha and Beta Rhythms between Right Inferior Frontal and Primary Sensory Neocortex
}

\author{
Matthew D. Sacchet, ${ }^{1,2 *}$ Roan A. LaPlante, ${ }^{3 *}$ Qian Wan, ${ }^{4}$ Dominique L. Pritchett, ${ }^{5}$ Adrian K.C. Lee, ${ }^{6,7}$ \\ Matti Hämäläinen, ${ }^{3}$ Christopher I. Moore, ${ }^{8}$ Catherine E. Kerr, ${ }^{9} \uparrow$ and Stephanie R. Jones ${ }^{3,8} \uparrow$ \\ ${ }^{1}$ Neurosciences Program, Stanford University School of Medicine, Stanford, California, 94305, ${ }^{2}$ Department of Psychology, Stanford University, Stanford, \\ California, 94305, ${ }^{3}$ Athinoula A. Martinos Center For Biomedical Imaging, Massachusetts General Hospital, Charlestown, Massachusetts, 02129, ${ }^{4}$ School of \\ Engineering and Applied Sciences, Harvard University, Cambridge, Massachusetts, 02138, ${ }^{5} \mathrm{McGovern}$ Institute for Brain Research, Massachusetts Institute \\ of Technology, Cambridge, Massachusetts, 02139, ' Institute for Learning and Brain Sciences, University of Washington, Seattle, Washington, 98195, \\ ${ }^{7}$ Department of Speech and Hearing Sciences, University of Washington, Seattle, Washington, $98195,{ }^{8}$ Department of Neuroscience and Brown Institute for \\ Brain Sciences, Brown University, Providence, Rhode Island, 02912, and ${ }^{9}$ Department of Family Medicine, Brown Alpert Medical School, Providence, \\ Rhode Island, 02912
}

The right inferior frontal cortex (rIFC) is specifically associated with attentional control via the inhibition of behaviorally irrelevant stimuli and motor responses. Similarly, recent evidence has shown that alpha (7-14 Hz) and beta (15-29 $\mathrm{Hz})$ oscillations in primary sensory neocortical areas are enhanced in the representation of non-attended stimuli, leading to the hypothesis that allocation of these rhythms plays an active role in optimal inattention. Here, we tested the hypothesis that selective synchronization between $r$ IFC and primary sensory neocortex occurs in these frequency bands during inattention. We used magnetoencephalography to investigate phase synchrony between primary somatosensory (SI) and $r$ IFC regions during a cued-attention tactile detection task that required suppression of response to uncertain distractor stimuli. Attentional modulation of synchrony between SI and $r I F C$ was found in both the alpha and beta frequency bands. This synchrony manifested as an increase in the alpha-band early after cue between non-attended SI representations and rIFC, and as a subsequent increase in beta-band synchrony closer to stimulus processing. Differences in phase synchrony were not found in several proximal control regions. These results are the first to reveal distinct interactions between primary sensory cortex and $r I F C$ in humans and suggest that synchrony between $r I F C$ and primary sensory representations plays a role in the inhibition of irrelevant sensory stimuli and motor responses.

Key words: attention; inferior frontal cortex; magnetoencephalography; primary somatosensory cortex; somatosensation; synchrony

\section{Introduction}

Synchronization of oscillatory activity between cortical regions is hypothesized to regulate information flow and to be integrally involved in the attentional modulation of intracortical communication (Fries, 2005, 2009; Jensen and Mazaheri, 2010; Schroeder and Lakatos, 2009; Kveraga et al., 2011; Siegel et al., 2012;

Received March 28, 2014; revised Nov. 4, 2014; accepted Dec. 8, 2014.

Author contributions: M.D.S., R.A.L., Q.W., D.L.P., A.K.C.L., M.H., C.I.M., C.E.K., and S.R.J. designed research; C.I.M., C.E.K., and S.R.J. performed research; M.D.S., R.A.L., Q.W., D.L.P., and A.K.C.L. analyzed data; M.D.S., R.A.L., A.K.C.L., M.H., C.I.M., C.E.K., and S.R.J. wrote the paper.

This work was supported by National Institutes of Health Grants P41RR14075, K25MH072941, K01AT003459, K24AT004095, R01-NS045130-01, and T32GM007484, and National Science Foundation Grants 0316933 and GRFP DGE-1147470. We thank David Badre and Michael Frank for help in shaping the scientific direction of the work; Tim Buschman for insight with regard to phase analyses; and Daniel Wakeman for contributions to inverse methods.

The authors declare no competing financial interests.

${ }^{*}$ M.D.S. and R.A.L. contributed equally to this work.

tC.E.K. and S.R.J. contributed equally to this work.

Correspondence should be addressed to Dr. Stephanie R. Jones, Brown University, Department of Neuroscience,

Providence, RI 02912.E-mail: Stephanie_Jones@brown.edu.

DOI:10.1523/JNEUROSCI.1292-14.2015

Copyright $\odot 2015$ the authors $\quad 0270-6474 / 15 / 352074-09 \$ 15.00 / 0$
Baldauf and Desimone, 2014; Bressler and Richter, 2014). Cognitive control regions in frontal cortex are thought to drive such modulation. However, there has been considerable debate regarding the specificity of the prefrontal regions involved, and the direction of modulation, particularly in the low-frequency alpha (7-14 Hz) (Sauseng et al., 2005; Siegel et al., 2008; Doesburg et al., 2009), and beta bands (15-29 Hz) (Buschman and Miller, 2007; Fritz et al., 2010; Buschman et al., 2012; Bressler and Richter, 2014; Womelsdorf et al., 2014), potentially due to differences in task parameters and cortical areas considered.

The right inferior frontal cortex (rIFC) has been implicated in mediating top-down attentional and behavioral control (Levy and Wagner, 2011; Hirose et al., 2013; Baldauf and Desimone, 2014). Extensive evidence exists for the involvement of rIFC in the dampening of responses to irrelevant stimuli (Hampshire et al., 2010; Gazzaley and Nobre, 2012; Weissman and Prado, 2012) and in motor response inhibition (i.e., stop signals) (Aron et al., 2004, 2014). Results from non-invasive brain stimulation suggest that rIFC causally mediates top-down inhibitory control (Chambers et al., 2007; Swann et al., 2009, 2012; Neubert et al., 2010; 
Zanto et al., 2011; Wessel et al., 2013; Gogulski et al., 2015). Evidence also suggests that rIFC subregions are differentially engaged in attentional monitoring and motor response inhibition. Anterior dorsal rIFC subregions, including right inferior frontal gyrus (rIFG) and inferior frontal sulcus (rIFS), are involved in attentional monitoring and reflexive reorienting, whereas more posterior ventral subregions, including the right inferior frontal junction (rIFJ), are additionally involved in stopping action (Sharp et al., 2010; Levy and Wagner, 2011; Baldauf and Desimone, 2014).

Considerable evidence suggests that primary sensory representations gate the flow of relevant sensory information to cortex and that attentional modulation of low-frequency (alpha and beta) power underlies this gating (Worden et al., 2000; Siegel et al., 2008; e.g., Jones et al., 2010). To date, there is no evidence of attentional modulation of synchrony between prefrontal cortex and topographically localized primary sensory representations in humans. This absence may be due to phase synchrony not acting as a mechanism for attentional control, or it may be that phase synchrony is limited to more proximal regions in the neocortical hierarchy.

Here, we used magnetoencephalography (MEG) to test the hypothesis that a cued-attention tactile detection task, which explicitly required suppression of distractor stimuli in non-attended representations, would selectively engage low-frequency synchrony between a topographically localized primary somatosensory cortex (SI) representation and rIFC. We additionally hypothesized that anatomically identified rIFC subregions (i.e., rIFS and rIFJ) may differentially synchronize with SI. This study extends prior work in which we showed that attention modulates alpha and beta components of the somatosensory mu-rhythm during the same cued-attention tactile detection task (Jones et al., 2010).

\section{Materials and Methods}

The data analyzed in this study were used in prior investigations of attentional modulation of alpha and beta power in SI. Subject recruitment, experimental protocol, and data acquisition have been explained in detail previously (Jones et al., 2010; Kerr et al., 2011; Wan et al., 2011) and are reviewed below. The novel source estimation and data analysis performed in this study are detailed.

Subjects and experimental design. Data were collected from 12 healthy, right-handed adults (mean \pm SD: age, $31.6 \pm 7$ years; 11 female). During MEG data acquisition, subjects' hands and feet rested on plastic frames through which tactile stimuli ( $10 \mathrm{~ms}$ duration) were delivered to the left hand (third digit) and left foot (first digit) using a piezoelectric device (Noliac). We performed localization trials to functionally identify subject-specific SI hand regions (hSI), in addition to cued-attention trials in which subjects completed a cued-attention tactile discrimination task. During localization trials, suprathreshold tactile stimuli were administered to the third digit of the left hand. These data was used to localize the left hand representation in SI. Localization runs were $3 \mathrm{~min}$ in duration, with $3 \mathrm{~s}$ trials. Each subject completed at least three localization runs. During cued-attention trials, a visual cue instructed subjects to allocate attention in anticipation of a brief, threshold-level tactile stimulus to the "hand," "foot," or "either" (i.e., hand or foot). Tactile stimulation was counterbalanced by area and jittered, occurring at least $1000 \mathrm{~ms}$ after the cue on the distal pad of the left hand or foot. On an individual subject basis, initial stimulus thresholds were identified using a Parameter Estimation Sequential Testing convergence algorithm (Leek, 2001). Three minutes of data was used for this procedure. The Parameter Estimation Sequential Testing procedure consists of series of three-trial sets, including a strong, moderate, and minimum stimulus that change strengths dynamically depending on subject detection. The first three-trial set is comprised of a strong stimulus ( $100 \%$ amplitude, $350 \mu \mathrm{m})$, then a weak stimulus (50\% amplitude), and last a blank stimulus. When the subject reports detection of both the strong and weak stimulus, the strong stimulus magnitude is halved, the moderate stimulus magnitude is replaced with the mean of moderate and weak stimuli magnitudes, and the weak stimulus magnitude stays the same. When the subject fails to detect the moderate stimulus, the strong stimulus does not change, and the minimum stimulus is replaced by the middle stimulus, and the moderate stimulus is replaced by the mean of the strong and the moderate stimulus. This three-trial set procedure was iterated until the difference in the middle stimulus between the last two trials was $<5 \mu \mathrm{m}$.

During MEG data collection in cued-attention runs, intensity was maintained at a $66 \%$ detection level across all attend condition (hand, foot or either) using a dynamic algorithm. If two correct responses were made, the threshold-level voltage sent to the piezoelectric was decreased by $0.005 \mathrm{~V}$ (a change of $\sim 4.5 \mu \mathrm{m}$ in piezoelectric movement), and the correct response counts were reset to zero. In contrast, if three incorrect responses were made, the voltage was increased by $0.005 \mathrm{~V}$. Additionally, suprathreshold (100\% detection) and null-threshold ( $0 \%$ detection) stimuli were randomly interleaved for a $10 \%$ and $20 \%$ of trials, respectively.

At least $400 \mathrm{~ms}$ after the stimulus, when the visual cue changed to a fixation cross, subjects reported via right-hand button press (see Fig. $1 \mathrm{~A}$ ) detection or non-detection of tactile stimulation in the attended location. Here we report on data from the pretactile stimulus period, from ( -200 to $1000 \mathrm{~ms}$ relative to the visual cue). Subjects completed at least five cued-attention runs with at least 40 trials per run (mean \pm SD: total trials, $562.8 \pm 69.0$ ).

We were unable to compare phase-locking values (PLVs) across detected and not detected trials as subjects only reported detection in attended trials, and the majority of attended hand trials were detected. The total number of trials in which attention was cued to the hand and subjects reported stimulus detection was $82.5 \pm 11.3$ (mean $\pm \mathrm{SD}$ ), whereas the number of attended and non-detected trials was $9.9 \pm 5.8$ (mean \pm $\mathrm{SD})$; thus, this analysis was underpowered. Additionally, our study was not designed to assess relations between PLV and reaction time, as subjects were cued to respond to detection, limiting reaction time variability.

MEG and MRI data acquisition. Data were recorded using a 306 channel MEG with 102 magnetometers and 204 planar gradiometers located at 102 locations around the scalp (dc-SQUID VectorView system, ElektaNeuromag) inside a magnetically shielded room (IMEDCO). Data were collected at a $600 \mathrm{~Hz}$ sampling rate and filtered to a $0.1-200 \mathrm{~Hz}$ bandpass. Both horizontal and vertical bipolar EOG were collected for eye movement-related artifact rejection. High-resolution T1-weighted anatomical MRIs (3.0T Trio, Siemens) were collected for coregistration using standard procedures. The FreeSurfer software suite (http://surfer. nmr.mgh.harvard.edu) was used for surface reconstruction and cortical labeling (Dale et al., 1999). Structurally defined cortical labels were automatically generated using Destrieux and Desikan-Killiany parcellation methods (Fischl et al., 2002, 2004; Desikan et al., 2006; Destrieux et al., 2010). Using Elekta-Neuromag's MaxFilter software, temporal signal space separation (tSSS) was implemented on sensor data to minimize extracranial noise (Taulu et al., 2005). The tSSS method uses Maxwell's equations to minimize magnetic sources located outside the sensor array. To mitigate effects from powerline noise $(60 \mathrm{~Hz})$ and aliasing, sensor level data was low-pass filtered at $50 \mathrm{~Hz}$.

$M E G$ source space signal estimation. In contrast to our prior studies, which used an equivalent current dipole fitting procedure (Jones et al., 2010; Kerr et al., 2011; Wan et al., 2011), in this study minimum norm estimates (MNEs) were calculated on a subject-by-subject basis using the MNE software suite (Gramfort et al., 2014). MNE calculates distributed dipoles by minimizing the norm of estimated currents within the brain, allowing for the projection of signals from sensor space to the cortical surface (i.e., source space). The MNE software suite facilitated MEGMRI coregistration, construction of cortically constrained source, conductivity, and forward and inverse models (Hämäläinen and Sarvas, 1989; Dale and Sereno, 1993; Hämäläinen and Ilmoniemi, 1994; Dale et al., 1999; Mosher et al., 1999; Liu et al., 2002; Fischl et al., 2004; Jovicich et al., 2006). MEG-coordinate frames were manually aligned to anatomical MRI data using fiducial points and subsequently automatically 
calibrated using an Iterative Closest Point algorithm (15 iterations). Forward solutions were estimated using single-layer homogeneous boundary-element models (the inner skull surface was segmented to 5120 triangles). Inverse operators were then estimated. For synchrony analysis, inverse operators were calculated using empty room noise covariance matrices in conjunction with depth weighting and loose orientation constraints (Lin et al., 2006). For functional localization, a similar procedure was used to estimate MNEs, with several key differences: a $200 \mathrm{~ms}$ pretactile stimulus period was used for the noise covariance matrix and activity was estimated using a normalized MNE (dynamic statistical parametric mapping [dSPM] ). An empty room noise covariance matrix was used for synchrony analysis to reduce attenuation of preattentional cue rhythmic activity (i.e., spontaneous rhythmic activities). In contrast, the functional localizer task is explicitly postattentional cue, and thus attenuation of preattentional cue activity was important to specifically reveal stimulus-evoked activities.

Defining ROIs. For the localization of hSI, peak tactile-evoked responses were extracted from the Desikan-Killiany postcentral cortical label of localization trials. To identify an approximate window in which the peak evoked response occurred, these trial-averaged current distributions were manually inspected from a $40-70 \mathrm{~ms}$ post-tactile stimulus window, which was previously shown to contain a prominent peak response to this tactile stimulus (Jones et al., 2007). Responses were visualized on rendered inflated cortical surfaces (manually identified approximate time interval start/end, mean \pm SD: $54.6 / 71.3 \pm 4.8 / 5.1 \mathrm{~ms}$ ), and dSPM estimates were extracted from each vertex of the label, for each time point in the manually identified time window. This resulted in millisecond-by-millisecond poststimulus dSPM estimates from the postcentral label in which the hand-related evoked response occurred. The precise time point of maximum dSPM value across all postcentral vertices was

then algorithmically identified. The top $7.5 \%$ most active dipoles at this precisely identified time point were defined as hSI. If a vertex in the ROI was $\geq 5$ vertices from the largest contiguous mass of vertices, it was replaced by the next most active vertex (for an example hSI, see Figure $1 B)$.

As in our prior studies (Jones et al., 2010; Kerr et al., 2011), we had difficulty localizing the foot area of SI (fSI) using a similar procedure. Difficulty in localizing fSI using MEG is thought to be the result of low signal amplitudes from the foot (and lower limbs more generally) as detected by MEG (Nakamura et al., 1998). Here, in an attempt to analyze fSI, we used average peak response to suprathreshold stimulation to the left first digit toe and defined fSI ROIs as $\geq 14$ vertices clustered near the midline in the Desikan paracentral lobule cortical label. We were only able to identify fSI in 8 of the 12 participants. Analysis of alpha and beta PLV between fSI and rIFC in these 8 subjects revealed no statistical significance. We view these results as underpowered and inconclusive.

Anatomically defined cortical labels based on the Destrieux cortical atlas (Destrieux et al., 2010) were used to define rIFC subregions. These labels were not selected based on source-localized activity patterns but rather selected based on predefined atlas parcellations with regions chosen $a$ priori. As MEG predominately detects signals tangential to the cortical surface and MNE preferentially attributes signals to the cortical surface, ROIs were restricted to labels anatomically defined within cor- tical sulci; however, this does not completely rule out possible contribution from gyri (Hillebrand and Barnes, 2002). Specifically, based on prior literature and a priori hypotheses, we examined synchrony between hSI and two subregions of rIFC (i.e., right IFS and IFJ, rIFS and rIFJ, respectively) (Sharp et al., 2010; Levy and Wagner, 2011; Baldauf and Desimone, 2014). These regions were anatomically identified using Destrieux parcellation labels referred to as IFS, and as the anterior vertical ramus of the Sylvan fissure at the intersection of the posterior end of the IFS and the precentral sulcus, also known as IFJ (Baldauf and Desimone, 2014; Levy and Wagner, 2011) (see Fig. 1B). Because of individual differences in cortical morphometry, in two subjects the rIFJ could not be well defined. These subjects were omitted from analyses related to the rIFJ.

Signal extraction. For a given ROI, vertex-wise signals were averaged to compute synchrony and spectral power analyses. To address the possibility of signals partially cancelling each other due to variation in dipole orientations, before signal averaging, signals from different vertices were aligned within each subject's ROI during the computation of inverse solutions from the raw data. Specifically, first the surface normals within the label were organized in an $n$ (vertices) $\times 3$ matrix. The preferred orientation was then calculated from the $n \times 3$ matrix by taking the first right singular vector, which is its largest singular value. If, after taking the dot product of the surface normal of a vertex, the result was negative, then the signal estimates at this vertex were inverted. This procedure was 
implemented via the align_z option of the mne_compute_raw_inverse function from the MNE software suite. Thus, align_z ensures that signals do not cancel due to the interaction of geometry and the arbitrary assignment of positive and negative activities in source space. We acknowledge that such alignment could bias toward homogeneous PLVs (as defined below), even if their sign is heterogeneous, and hence overestimate the PLV. Given the complementary nature of our results with prior literature on the role of IFC, we do not think this has significantly confounded our results.

Phase synchrony analysis. Synchrony was estimated on a trial-by-trial manner by calculating PLVs between signals from hSI and rIFC subregions. PLV quantifies synchrony by assessing variance in phase relations between signals at a given frequency (Lachaux et al., 1999). After aligning and averaging vertex-wise signals for each ROI, PLVs were calculated millisecond by millisecond from -733 to $1333 \mathrm{~ms}$ relative to visual attention cue onset, from 1 to $50 \mathrm{~Hz}$ ( $1 \mathrm{~Hz}$ step). The beginning and ending periods were discarded to prevent signal smearing effects at the edge of the wavelet; only values from -200 to $1000 \mathrm{~ms}$ relative to the cue were considered for further analysis (see Fig. 2). Both signals $\left(s_{i}^{a}\right.$ and $s_{i}^{b}$ ) were first convolved with a Morlet wavelet as follows:

$$
w\left(t, f_{0}\right)=A \exp \left(-t^{2} / 2 \sigma_{t}^{2}\right) \exp \left(2 i \pi f_{0} t\right)
$$

with normalization factor $A$ equal to:

$$
\left(\sigma_{t} \sqrt{\pi}\right)^{-\frac{1}{2}}
$$

This results in a complex representation of phase for trial $i$, time $t$ and frequency $f_{0}$ for each signal (here $s_{i}^{a}$ ):

$$
\Phi_{i}^{a}\left(t, f_{0}\right)=\frac{w\left(t, f_{0}\right) * s_{i}^{a}(t)}{\left|w\left(t, f_{0}\right) * s_{i}^{a}(t)\right|}
$$

The width of the wavelet $\left(m=f_{0} / \sigma_{\mathrm{f}}\right)$ was selected as 7 ; with $\sigma_{f}=1 / 2 \pi \sigma_{\mathrm{t}}$. Finally, PLVs were calculated across $N$ trials between signals $s_{i}^{a}$ and $s_{i}^{b}$ :

$$
P L V\left(t, f_{0}\right)=\frac{1}{N} \sum_{i=1}^{N}\left(\Phi_{i}^{a} / \Phi_{i}^{b}\right)
$$

The modulus of which is PLV. PLV is thus a measure of intertrial variability of phase between two signals at time $t$, ranging from 0 to 1 ( 1 indicating perfect phase synchrony).

Statistical analysis of PLVs. Consistent with previous work indicting dominance of 7-14 Hz alpha and 15-29 Hz beta frequency bands in human SI MEG measured signals (Tiihonen et al., 1989; e.g., Jones et al., 2009, 2010), PLVs between SI and the frontal regions considered were dominant in these bands (see Fig. 2). Therefore, for all analyzes, PLV was averaged across the $7-14 \mathrm{~Hz}$ alpha band and $15-29 \mathrm{~Hz}$ beta band to test the $a$ priori hypotheses that synchrony would occur in these bands.

Statistically significant differences in PLVs between the attend-out (foot) versus attend-in (hand) condition were assessed using a binned analysis. Data were binned and averaged in $200 \mathrm{~ms}$ intervals in a $0-1000$ ms postcue period, as in our prior study (Kerr et al., 2011). These data were analyzed as percentage change from baseline, with baseline defined as -200 to $0 \mathrm{~ms}$ previsual cue across both conditions. As components of the data were non-normally distributed (Lilliefors test, $p<0.01$ ), nonparametric statistics (paired Wilcoxon sign-rank test) were used. Bonferroni correction was implemented for correction of multiple comparisons (five bins: $0.05 / 5=0.01$ ). Time-binned data meeting criteria at $p<0.01$ were considered significant, and $p<0.05$ was considered a statistical trend.

Analysis of power. To understand whether changes in power might drive synchrony-related effects, we additionally investigated attentional power modulation. As with PLV, we calculated power by convolving signal time courses with a complex Morlet wavelet with width 7. Spectral power time-frequency representations were computed from the squared magnitude of the complex wavelet-transformed data, as in our prior work (Jones et al., 2010). Power was statistically analyzed in the same manner as PLV using five $200 \mathrm{~ms}$ bins postattentional cue, with Bonferroni multiple comparison correction across time bins.
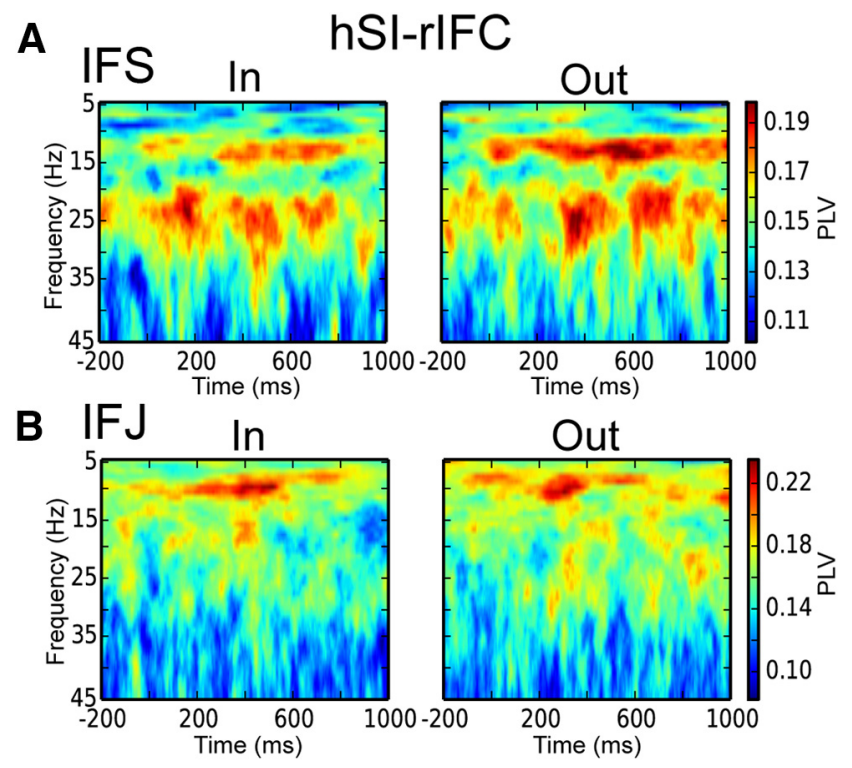

Figure 2. Depiction of PLVs with the hSI across time and frequency for attend-out and attend-in attentional conditions for rIFC: $\mathrm{rIFS}(\boldsymbol{A})$ and $\mathrm{rIFJ}(\boldsymbol{B})$. In both attentional conditions, PLVs are highest in the $7-14 \mathrm{~Hz}$ alpha and $15-29 \mathrm{~Hz}$ beta frequencies, with greater values visible in the attend-out condition.

Assessment of laterality. As a control to assess the laterality of observed PLV effects, we additionally analyzed PLV from left lateralized IFC subregions, left IFS (IIFS) and left (IIFJ). As with the right hemisphere, the left-lateralized ROIs were identified using anatomical parcellation according to the Destrieux atlas. PLV and power were analyzed using the same binned procedure as the right hemisphere.

Volume conduction analysis. We tested the possible contribution of volume conduction to our results in three ways. First, in addition to PLV, we examined the imaginary component of PLV (iPLV), a metric robust to volume conduction artifacts that additionally accounts for deep sources that are difficult to measure directly (Nolte et al., 2004). Second, we calculated source-space signal crosstalk between hSI and all other vertices on the cortical surface grid using a simulated signal. Crosstalk is defined as the contribution from multiple source signals to the signal localized at an individual source. The simulated signal (using a normal orientation to the surface) is generated from the lead field matrix. High crosstalk in rIFC would suggest volume-conduction-related confounding of PLV effects. Crosstalk was assessed for each individual in native space, with subsequent warping to the FreeSurfer group template. A group aggregate map was produced by averaging crosstalk across individuals in template space. Last, we assessed PLV in three control regions proximal to rIFC. These ROIs were defined using the Destrieux cortical parcellation and included the right middle frontal sulcus (rMFS), right inferior premotor cortex (rIPMC), and right lateral orbital sulcus (rLOS; see Fig. 1B).

\section{Results}

\section{Attention induces increases in alpha and beta synchrony} between rIFC and non-attended SI representations

We examined phase synchrony in the alpha and beta bands between hSI and rIFC subregions during a task in which subjects were cued to report detection of a threshold level tactile stimulation to either the hand or foot (Fig. 1A). Subjects were instructed to respond only to detection of stimulation in the attended region, despite the equal possibility of stimulation in the nonattended area. Thus, the task required suppression of stimulus processing and motor response to stimulation in the nonattended area.

Based on a priori hypotheses, we examined two parcellated subregions of rIFC defined anatomically using structural MRI. 
Table 1. Statistical comparison of PLV across attentional conditions ${ }^{a}$

\begin{tabular}{|c|c|c|c|c|c|c|c|c|c|c|}
\hline \multirow[b]{2}{*}{ ms bin } & \multicolumn{5}{|c|}{ Alpha PLV } & \multicolumn{5}{|c|}{ Beta PLV } \\
\hline & $0-200$ & $200-400$ & $400-600$ & $600-800$ & $800-1000$ & $0-200$ & $200-400$ & $400-600$ & $600-800$ & $800-1000$ \\
\hline rIFJ & $0.038^{* *}$ & 0.176 & 0.383 & 0.438 & 0.656 & 0.743 & 0.350 & 0.941 & $0.0058^{*}$ & $0.016^{* *}$ \\
\hline rIFS & 0.196 & $0.0009^{*}$ & $0.047^{* *}$ & 0.065 & 0.409 & 0.204 & 0.143 & 0.857 & $0.026^{* *}$ & $0.040^{* *}$ \\
\hline
\end{tabular}

${ }^{a}$ Statistical comparison of PLVs across attentional conditions. Attend-out - attend-in alpha and beta PLVs between signals from functionally defined hSI and rlFC, including rIFS and rIFJ. PLVs were averaged in $200 \mathrm{~ms}$ time windows after cue and compared across attentional conditions using two-tailed sign-rank tests.

*Significant difference ( $p<0.01$, using Bonferroni correction for multiple comparisons across five time bins).

**Statistical trend $(p<0.05)$.

One of these regions constituted the anterior dorsal portion of rIFC, referred to as rIFS, and the other region constituted the posterior ventral portion of rIFC, referred to as rIFJ (Fig. 1B). These regions are known to have distinct cytoarchitectonic profiles (Amunts and Cramon, 2006) and to exhibit functional and anatomical specificity from neighboring regions (Chikazoe et al., 2009; Sharp et al., 2010; Levy and Wagner, 2011; Derrfuss et al., 2012). PLVs were compared between hSI and each region across attentional conditions (attend-out $=$ attention to foot; or attend-in = attention to hand) in the postcue period before tactile stimulation. This period is marked in Figure $1 \mathrm{~A}$ (dashed line).

Figure 2 depicts average time-frequency representations of PLVs between hSI and rIFC subregions for attend-in (left panel) and attend-out (right panel) conditions across subjects, from 5 to $45 \mathrm{~Hz}$ and -200 to $1000 \mathrm{~ms}$ around the cue during. The highest PLV values were restricted to the alpha and beta bands, with greater values in the attend-out condition. All further analyses were thus restricted to these bands.

Statistical significance of differences in PLVs across conditions (attend-out and attend-in) was assessed between hSI and each rIFC subregion in $200 \mathrm{~ms}$ bins (Table 1). This analysis revealed significant differences in alpha band PLVs between attendout and attend-in conditions in the early 200-400 ms postcue period between hSI and rIFS $(p<0.001)$, with a subsequent trend in the $400-600 \mathrm{~ms}$ period ( $p<0.05$; Fig. $3 A$ ). Specifically, greater alpha synchrony occurred during the attend-out compared with the attend-in condition. Trend differences in alpha synchrony were also observed between hSI and rIFJ 0-200 ms $(p<0.05)$.

In the beta band, significantly greater synchrony was observed in the attend-out compared with the attend-in condition between hSI and rIFJ in the later 600-800 ms bin $(p<0.01)$, with a continued trend in the $800-1000 \mathrm{~ms}$ bin $(p<0.02$; Fig. $3 B)$. Statistical trends were also observed in the beta band between hSI and rIFS in both of these bins $(600-1000 \mathrm{~ms}, p<0.05)$.

\section{Synchrony and attentional modulation of spectral power}

To assess whether the attentional PLV modulation might be driven by changes in spectral power, we additionally investigated attentional power modulation in all three regions (Table 2). Differences in power with attention were observed only in hSI in the beta band $600-800 \mathrm{~ms}$ after cue $(p<0.01)$ : a time window that overlapped with the PLV differences. As power differences were not found in any of the IFC regions, we conclude that power effects are not the primary driver of the PLV results. We note that the current results differ from our prior work (Jones et al., 2010). Specifically, here we did not find attentional effects in hSI alpha power, and the hSI beta power results vary slightly in the window of significance. This is likely due to differences in the inverse solution techniques used. In the current work, we use MNE, whereas our prior work used single dipole modeling. As such, the
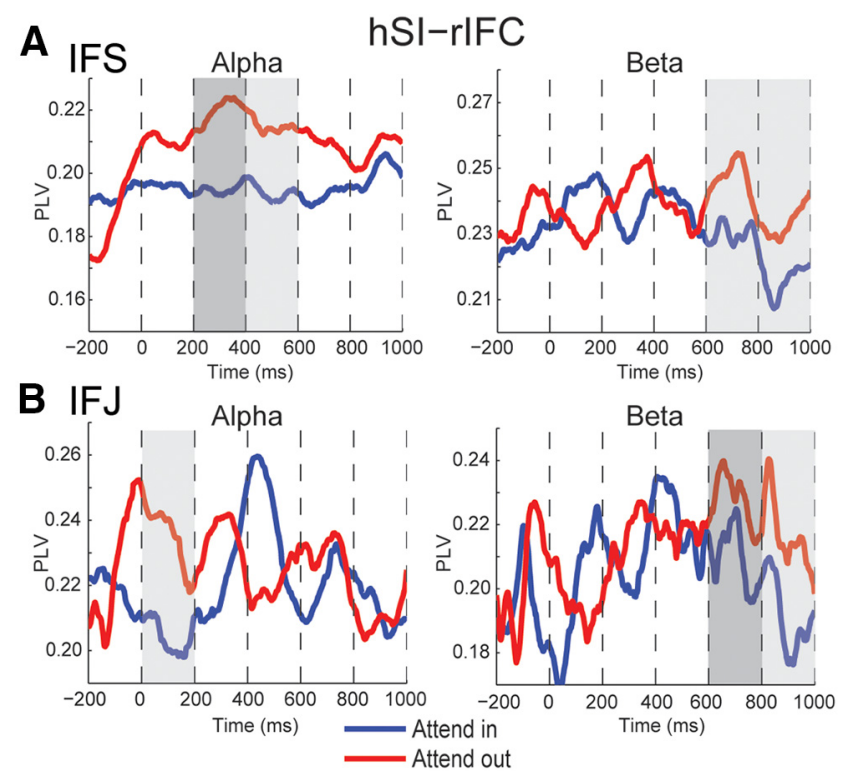

Figure 3. Temporal evolution of alpha and beta synchrony between $\mathrm{hSI}$ and $\mathrm{rlFC}$ in attend-in (blue) and attend-out (red) conditions. PLV data are presented between hSI and rIFS subregions. $\boldsymbol{A}$, rIFS. $\boldsymbol{B}$, rIFJ. Dark gray shading represents time bins exhibiting statistically significant differences across attentional conditions. Light gray shading represents statistical trends (Table 1). Statistically significant differences in the alpha band were found in an early time bin between $\mathrm{hSI}$ and $\mathrm{rIFS}(200-400 \mathrm{~ms}, p<0.001)$ and in the beta band in a later time bin between $\mathrm{hSI}$ and $\mathrm{rIFJ}(600-800 \mathrm{~ms}, p<0.01)$. Trend differences in alpha synchrony between $\mathrm{hSI}$ and rIFS continued until $600 \mathrm{~ms}(p<0.05)$, and in the beta band between $\mathrm{hSI}$ and rIFJ until $1000 \mathrm{~ms}$ $(p<0.02)$ with a similar trend between hSI-rIFS $(600-1000 \mathrm{~ms}, p<0.05)$. No significant differences were found in control regions around rIFC shown in Figure $1 B$.

ROIs in the current study represent a smaller cortical volume than in our prior work.

\section{Laterality of synchrony effects}

To test whether synchronization was lateralized to rIFC, we also examined synchrony between hSI and IIFC subregions (IIFS and IIFJ). Significant differences across attentional conditions were observed in alpha band PLVs between hSI and IIFS, in the 200$400 \mathrm{~ms}$ postcue period $(p<0.01)$. No other significant differences or trends were found. These effects appeared across attentional conditions despite that the mean raw PLVs were an order of magnitude larger in rIFS than lIFS (mean \pm SD: baseline rIFS, $0.18 \pm 0.0074$; baseline lIFS, $0.075 \pm 0.0027)$. No differences in power across attentional conditions were found in IIFS.

\section{Influence of volume conduction}

Based on three different analyses, we concluded that the observed synchrony effects between hSI and rIFC were not influenced by volume conduction. First, we examined the imaginary component of PLV, a metric robust to volume conduction artifacts that additionally accounts for deep sources that may be difficult to 
Table 2. Statistical comparison of power across attentional conditions ${ }^{a}$

\begin{tabular}{|c|c|c|c|c|c|c|c|c|c|c|}
\hline \multirow[b]{2}{*}{ ms bin } & \multicolumn{5}{|c|}{ Alpha power } & \multicolumn{5}{|c|}{ Beta power } \\
\hline & $0-200$ & $200-400$ & $400-600$ & $600-800$ & $800-1000$ & $0-200$ & $200-400$ & $400-600$ & $600-800$ & $800-1000$ \\
\hline hSI & 0.519 & 0.301 & 0.301 & 0.470 & 0.052 & 0.053 & 0.064 & 0.129 & 0.077 & $0.005^{*}$ \\
\hline rIFJ & 0.922 & 0.160 & 0.846 & 0.193 & 0.922 & 0.131 & 0.160 & 0.846 & 0.322 & 0.065 \\
\hline rIFS & 0.339 & 0.176 & 0.424 & 0.204 & 0.129 & 0.910 & 0.380 & 0.129 & 0.424 & 0.339 \\
\hline
\end{tabular}

${ }^{a}$ Statistical comparison of differences (attend-out - attend-in) in power across attentional conditions. Power differences were assessed in functionally defined hSI, rlFS, and rlFJ. Values shown are $p$ values from a two-tailed sign-rank test. *Significant difference ( $p<0.01$, significance after Bonferroni correction for multiple comparisons across five time bins). No trends $(p<0.05)$ were observed.

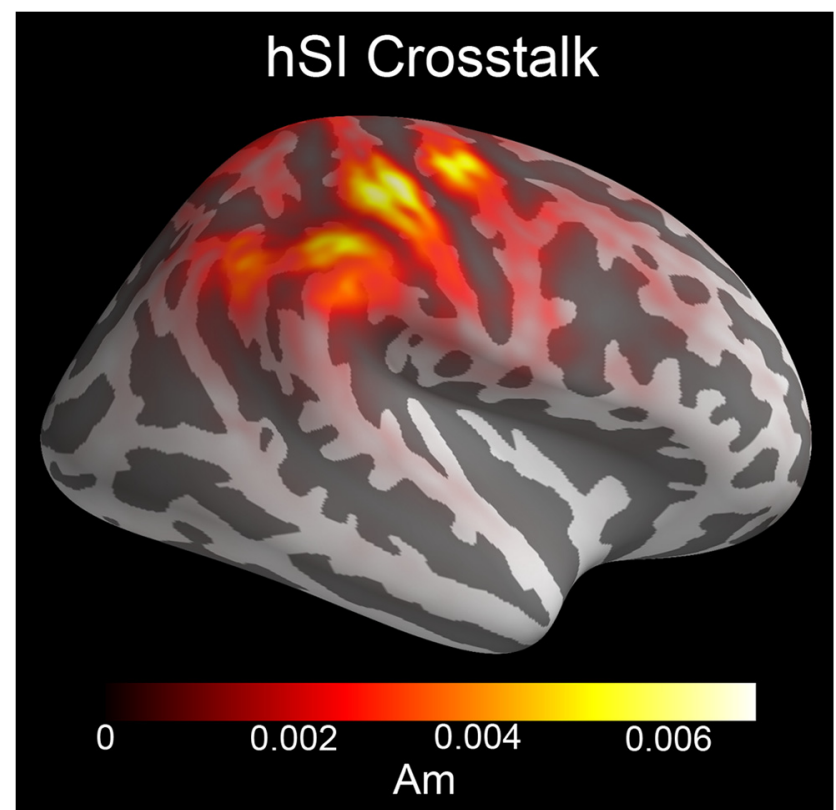

Figure 4. Signal crosstalk of hSI in the right hemisphere. Crosstalk was low between hSI and IFC regions where significant attentional differences in synchrony were found (see Fig. 1B), suggesting that volume conduction from hSI did not drive the observed synchrony effects between hSI and rIFC.

measure directly (iPLV) (Nolte et al., 2004; Ewald et al., 2012; Sadaghiani et al., 2012). A significant difference of iPLV between hSI and rIFJ in the 600-800 ms window was preserved in the beta band, suggesting that PLV results from this area and time window are not influenced by volume conduction from areas surrounding hSI or rIFJ. Significant differences were not found in the alpha band between hSI and rIFS; thus, we could not completely rule out the possibility of volume conduction effects influencing the alpha synchrony results using iPLV. Second, we examined the signal crosstalk of hSI. Crosstalk analysis revealed that signal mixing between hSI and rIFC was likely not related to the observed attentional modulation of synchrony, as hSI crosstalk was minimal with rIFC (Fig. 4). Third, we examined hSI synchrony with three anatomically defined control regions surrounding rIFC (rMFS, rIPMC, and, rLOS; Fig. 1B). No significant differences were observed in any control region. The lack of statistically significant differences in synchrony between hSI and areas surrounding rIFC additionally discounts the influence of volume conduction and suggests the observed synchrony effects are specific to rIFC.

\section{Discussion}

The current results indicate that cued attention to tactile stimulation modulates anticipatory alpha and beta synchrony between a topographically source localized region of SI and anatomically defined subregions within the rIFC. Attentional modulation of alpha synchrony was found early after the cue (200-600 ms) between hSI and rIFS. In contrast, modulation of beta synchrony was found closer to stimulus processing and motor response (600-1000 ms after cue) between hSI and rIFJ, with a trend in rIFS. As discussed below, we conjecture that the observed increase in interareal alpha synchrony with non-attended representations early after the cue may reflect anticipatory "inhibition" of irrelevant sensory information, whereas the subsequent beta synchrony may relate to mechanisms involved in facilitating accurate somatosensory detection and motor response. The unexpected finding of alpha synchrony between hSI and IIFC early after the cue (200-400 ms) may be related to retrieval of the appropriate stimulus-response rule associated with the attentional cue. These results are the first to show differential engagement of alpha and beta synchrony between primary sensory cortex and IFC in humans.

\section{The role of rIFC in inhibition of processing}

The rIFC has been identified as having an important role in mediating top-down attention via inhibition of non-relevant sensory information and motor actions, and has been explicitly implicated as part of the stop-signaling pathway in motor control (Hampshire et al., 2010; Neubert et al., 2010; Levy and Wagner, 2011; Swann et al., 2012; Weissman and Prado, 2012; Hwang et al., 2014). However, the precise role and temporal precision of the rIFC in meditating inhibitory control of perception and/or action are unclear. Our results indicate that low-frequency synchronization with primary sensory cortex may be involved in this processing.

A recent review suggests that rIFC subregions may be differentially engaged in attentional processes and motor control, with more anterior regions encoding higher-order goals (e.g., reflexive reorienting) whereas more posterior regions additionally encode more specific subgoals (e.g., action plans) (Levy and Wagner, 2011). Similarly, anterior-to-posterior medial frontal segregations have been shown to differentiate attentional capture and action inhibition (Sharp et al., 2010). Our results can be interpreted within this context, as we found that relatively anterior rIFC (i.e., rIFS) showed early effects in the alpha band specific to the attentional cues (greater alpha synchrony with non-attended representations in SI), which may act to inhibit distraction in irrelevant areas. In contrast, the relatively posterior ventral region (i.e., rIFJ) was differentially engaged in the beta band closer to the time of stimulus processing (greater beta synchrony with nonattended SI representation). This may be related to maintaining the inhibition of irrelevant representations and to inhibiting motor responses to stimulation in the irrelevant area. A similar statistical trend in beta was observed between hSI and rIFS.

Studies using fMRI suggest that $\mathrm{rIFG}$ is recruited when important cues are detected, regardless of whether the detection is followed by inhibition of a motor response (Hampshire et al., 2010). However, causal manipulation of presumed rIFG with transcranial magnetic stimulation has directly impacted "stop signal" 
motor responses (Chambers et al., 2007; Neubert et al., 2010), suggesting at least part of rIFG is involved in motor control. Our findings may help to disambiguate the role of rIFC in cue detection versus motor inhibition, such that cue detection processes involves alpha synchronization whereas motor inhibition involves beta synchronization (Zanto et al., 2011; Gogulski et al., 2015).

\section{Alpha synchrony: rIFS and the attentional modulation to "inhibit" distraction}

Attentional modulation of alpha activity acts in a topographically specific manner to gate the flow of sensory information in cortex such that increased alpha power correlates with inhibition of sensory information across modalities (Worden et al., 2000; Klimesch et al., 2007; Jones et al., 2010; Klimesch, 2012; Kerr et al., 2013). We conjecture that, similar to commonalities in modulation of alpha power, the observed increase in primary sensory to right frontal alpha synchrony in non-attend conditions is a generalizable feature of cortical dynamics that facilitates perception during distraction.

Other studies have investigated attentional modulation of interareal alpha synchrony with parietal association areas. Consensus has not been reached regarding the direction of modulation, likely due to differences in the spatial localization and imaging modalities studied (Sauseng et al., 2005; Siegel et al., 2008). Similar to our investigation, Doesburg et al. (2009) studied alpha synchrony between source-localized low-level sensory areas, in this case visual cortex (inferior occipital gyrus), and rIFC, using EEG. They found no effect on synchronization between visual cortex and $r I F C$, and report an increase in alpha synchrony with attention between inferior occipital gyrus and superior parietal lobe. This contrasts with our findings of synchrony between lowlevel somatosensory representations and rIFC. There are a number of possible explanations for this discrepancy, including the increased spatial specificity in the current MEG study, MEG biases to sulcal rather than gyral activity (Hillebrand and Barnes, 2002), and/or differences in the probability of distracting stimuli in each paradigm, as distraction occurred more often in our paradigm (Doesburg et al., 2009, 50\% compared with 20\%). This difference suggests that the blocking of distraction may be a key factor in engaging $r I F C$ alpha synchrony with primary sensory cortex. Concordant with our results, an intracranial LFP study in behaving ferrets reports greater low frequency $(10-20 \mathrm{~Hz})$ synchrony between primary auditory cortex and prefrontal cortical sites during passive presentations of tone stimuli, compared with behaviorally relevant task conditions in a tone detection paradigm (Fritz et al., 2010).

\section{Alpha synchrony: IIFS and the selection of stimulus-response contingencies}

The majority of studies of IFC suggest that attention-driven inhibitory control is restricted to the right hemisphere (Aron et al., 2004, 2014; Levy and Wagner, 2011), although some EEG evidence shows bilateral engagement of IFG in top-down attentional control (Green and McDonald, 2008). The IIFC has more often been associated with the cognitive control of memory, facilitating the retrieval of rules and selection of the proper response given contingencies associated with the rule (Badre and Wagner, 2007; Bunge, 2004; Donohue et al., 2005; Sakai and Passingham, 2003). The middle ventrolateral and dorsolateral regions of the left PFC in particular have been related to rule based response selection (Bunge, 2004) and postretrieval resolution of competition among active representations (Badre and Wagner, 2007). In this context, our observation of early and brief synchrony between hSI and IIFS alpha synchrony (200-400 ms after cue) may be related to the rapid selection of the appropriate stimulus-response rule associated with the contingency to attend-in versus attend-out, rather than a longer lasting top-down inhibitory signal that is mediated by the $r I F C$.

\section{Beta synchrony: attentional modulation to mediate "stop signaling"}

Similar to alpha, topographically precise attentional modulation of beta power in sensory cortex has been observed, with higher power inversely correlated with perception (Bauer et al., 2006; Dockstader et al., 2010; Jones et al., 2010; van Ede et al., 2012). Beta activity is also explicitly tied to motor function, as beta rhythms have been observed in many nodes of the motor pathway in contraction or hold conditions (Leventhal et al., 2012; Miller et al., 2012). This beta activity has been hypothesized to maintain the continuation of currently active rules or motor plans (Engel and Fries, 2010) or to reflect an increased "offline" processing mode during motor decision making (Haegens et al., 2011). The latter conceptualization is consistent with our findings of increased beta synchronization when inhibition of a nonrelevant area was necessary for both the detection decision and motor response.

The rIFC has been explicitly implicated in "stop signaling," probably mediated by a top-down signal to subthalamic nucleus and basal ganglia structures, and/or premotor cortex, which all exhibit beta rhythmicity during these conditions (Kühn et al., 2004; Swann et al., 2011; Wessel et al., 2013). rIFC beta synchrony with primary motor and premotor cortex has been explicitly associated with successful execution of stop compared with unsuccessful stop trials (Swann et al., 2009, 2011, 2012). The current finding of increases in beta synchrony between hSI and rIFC during non-attention appears to act as an inhibitory signal to take the non-attended representation offline from the detection process. This beta synchrony may also be related to inhibiting the motor response program, as subjects had to "stop" button press responses to felt stimuli in the non-attended representation. We did not find a significant difference in beta synchrony with attention between hSI and the anatomically defined rIPMC control region, suggesting that the observed synchrony effects between hSI and rIFC may be mediated by subcortical structures rather than premotor cortex (Swann et al., 2009).

Computational neural modeling has shown that beta frequency oscillations can emerge from the integration of two alpha frequency excitatory drives to granular and supragranular layers of neocortex (Jones et al., 2009; Ziegler et al., 2010). These results suggest that beta frequency input to SI is not required to observe beta synchrony between hSI and IFC, but rather a third source may drive both areas (Schmiedt et al., 2014). Further studies are necessary to explicitly delineate the mechanisms of coordination.

\section{References}

Amunts K, von Cramon DY (2006) The anatomical segregation of the frontal cortex: what does it mean for function? Cortex 42:525-528. CrossRef Medline

Aron AR, Robbins TW, Poldrack RA (2004) Inhibition and the right inferior frontal cortex. Trends Cogn Sci 8:170-177. CrossRef Medline

Aron AR, Robbins TW, Poldrack RA (2014) Inhibition and the right inferior frontal cortex: one decade on. Trends Cogn Sci 18:177-185. CrossRef Medline

Badre D, Wagner AD (2007) Left ventrolateral prefrontal cortex and the cognitive control of memory. Neuropsychologia 45:2883-2901. CrossRef Medline 
Baldauf D, Desimone R (2014) Neural mechanisms of object-based attention. Science 334:424. CrossRef Medline

Bauer M, Oostenveld R, Peeters M, Fries P (2006) Tactile spatial attention enhances gamma-band activity in somatosensory cortex and reduces lowfrequency activity in parieto-occipital areas. J Neurosci 26:490-501. CrossRef Medline

Bressler SL, Richter CG (2014) Interareal oscillatory synchronization in top-down neocortical processing. Curr Opin Neurobiol 32:62-66. CrossRef Medline

Bunge SA (2004) How we use rules to select actions: a review of evidence from cognitive neuroscience. Cogn Affect Behav Neurosci 4:564-579. CrossRef Medline

Buschman TJ, Miller EK (2007) Top-down versus bottom-up control of attention in the prefrontal and posterior parietal cortices. Science 315: 1860-1862. CrossRef Medline

Buschman TJ, Denovellis EL, Diogo C, Bullock D, Miller EK (2012) Synchronous oscillatory neural ensembles for rules in the prefrontal cortex. Neuron 76:838-846. CrossRef Medline

Chambers CD, Bellgrove MA, Gould IC, English T, Garavan H, McNaught E, Kamke M, Mattingley JB (2007) Dissociable mechanisms of cognitive control in prefrontal and premotor cortex. J Neurophysiol 98:3638-3647. CrossRef Medline

Chikazoe J, Jimura K, Asari T, Yamashita K, Morimoto H, Hirose S, Miyashita Y, Konishi S (2009) Functional dissociation in right inferior frontal cortex during performance of go/no-go task. Cereb Cortex 19:146-152. CrossRef Medline

Dale AM, Sereno MI (1993) Improved localization of cortical activity by combining EEG and MEG with MRI cortical surface reconstruction: a linear approach. J Cogn Neurosci 5:162-176. CrossRef Medline

Dale AM, Fischl B, Sereno MI (1999) Cortical surface-based analysis I. Segmentation and surface reconstruction. Neuroimage 9:179-194. CrossRef Medline

Derrfuss J, Vogt VL, Fiebach CJ, von Cramon DY, Tittgemeyer M (2012) Functional organization of the left inferior precentral sulcus: dissociating the inferior frontal eye field and the inferior frontal junction. Neuroimage 59:3829-3837. CrossRef Medline

Desikan RS, Ségonne F, Fischl B, Quinn BT, Dickerson BC, Blacker D, Buckner RL, Dale AM, Maguire RP, Hyman BT, Albert MS, Killiany RJ (2006) An automated labeling system for subdividing the human cerebral cortex on MRI scans into gyral based regions of interest. Neuroimage 31:968980. CrossRef Medline

Destrieux C, Fischl B, Dale A, Halgren E (2010) Automatic parcellation of human cortical gyri and sulci using standard anatomical nomenclature. Neuroimage 53:1-15. CrossRef Medline

Dockstader C, Cheyne D, Tannock R (2010) Cortical dynamics of selective attention to scholarly events. Neuroimage 49:1777-1785. CrossRef Medline

Doesburg SM, Green JJ, McDonald JJ, Ward LM (2009) From local inhibition to long-range integration: a functional dissociation of alpha-band synchronization across cortical scales in visuospatial attention. Brain Res 1303:97-110. CrossRef Medline

Donohue SE, Wendelken C, Crone EA, Bunge SA (2005) Retrieving rules for behavior from long-term memory. Neuroimage 26:1140-1149. CrossRef Medline

Engel AK, Fries P (2010) Beta band oscillations: signalling the status quo? Curr Opin Neurobiol 20:156-165. CrossRef Medline

Ewald A, Marzetti L, Zappasodi F, Meinecke FC, Nolte G (2012) Estimating true brain connectivity from EEG/MEG data invariant to linear and static transformations in sensor space. Neuroimage 60:476-488. CrossRef Medline

Fischl B, Salat DH, Busa E, Albert M, Dieterich M, Haselgrove C, van der Kouwe A, Killiany R, Kennedy D, Klaveness S, Montillo A, Makris N, Rosen B, Dale AM (2002) Whole brain segmentation: automated labeling of neuroanatomical structures in the human brain. Neuron 33:341355. CrossRef Medline

Fischl B, van der Kouwe A, Destrieux C, Halgren E, Ségonne F, Salat DH, Busa E, Seidman LJ, Goldstein J, Kennedy D, Caviness V, Makris N, Rosen B, Dale AM (2004) Automatically parcellating the human cerebral cortex. Cereb Cortex 14:11-22. CrossRef Medline

Fries P (2005) A mechanism for cognitive dynamics: neuronal communication through neuronal coherence. Trends Cogn Sci 9:474-480. CrossRef Medline

Fries P (2009) Neuronal gamma-band synchronization as a fundamental pro- cess in cortical computation. Annu Rev Neurosci 32:209-224. CrossRef Medline

Fritz JB, David SV, Radtke-Schuller S, Yin P, Shamma SA (2010) Adaptive, behaviorally gated, persistent encoding of task-relevant auditory information in ferret frontal cortex. Nat Neurosci 13:1011-1019. CrossRef Medline

Gazzaley A, Nobre AC (2012) Top-down modulation: bridging selective attention and working memory. Trends Cogn Sci 16:128-134. CrossRef Medline

Gogulski J, Boldt R, Savolainen P, Guzmán-López J, Carlson S, Pertovaara A (2015) A segregated neural pathway for prefrontal top-down control of tactile discrimination. Cereb Cortex 25:161-166. CrossRef Medline

Gramfort A, Luessi M, Larson E, Engemann DA, Strohmeier D, Brodbeck C, Parkkonen L, Hämäläinen MS (2014) MNE software for processing MEG and EEG data. Neuroimage 86:446-460. CrossRef Medline

Green JJ, McDonald JJ (2008) Electrical neuroimaging reveals timing of attentional control activity in human brain. PLoS Biol 6:e81. CrossRef

Haegens S, Nácher V, Hernández A, Luna R, Jensen O, Romo R (2011) Beta oscillations in the monkey sensorimotor network reflect somatosensory decision making. Proc Natl Acad Sci U S A 108:10708-10713. CrossRef Medline

Hämäläinen MS, Ilmoniemi RJ (1994) Interpreting magnetic fields of the brain: minimum norm estimates. Med Biol Eng Comput 32:35-42. CrossRef Medline

Hämäläinen MS, Sarvas J (1989) Realistic conductivity geometry model of the human head for interpretation of neuromagnetic data. IEEE Trans Biomed Eng 36:165-171. CrossRef Medline

Hampshire A, Chamberlain SR, Monti MM, Duncan J, Owen AM (2010) The role of the right inferior frontal gyrus: inhibition and attentional control. Neuroimage 50:1313-1319. CrossRef Medline

Hillebrand A, Barnes GR (2002) A quantitative assessment of the sensitivity of whole-head MEG to activity in the adult human cortex. Neuroimage 16:638-650. CrossRef Medline

Hirose S, Watanabe T, Wada H, Imai Y, Machida T, Shirouzu I, Miyashita Y, Konishi S (2013) Functional relevance of micromodules in the human association cortex delineated with high-resolution fMRI. Cereb Cortex 23:2863-2871. CrossRef Medline

Hwang K, Ghuman AS, Manoach DS, Jones SR, Luna B (2014) Cortical neurodynamics of inhibitory control. J Neurosci 34:9551-9561. CrossRef Medline

Jensen O, Mazaheri A (2010) Shaping functional architecture by oscillatory alpha activity: gating by inhibition. Front Hum Neurosci 4:1-8. CrossRef Medline

Jones SR, Pritchett DL, Stufflebeam SM, Hämäläinen M, Moore CI (2007) Neural correlates of tactile detection: a combined magnetoencephalography and biophysically based computational modeling study. J Neurosci 27:10751-10764. CrossRef Medline

Jones SR, Pritchett DL, Sikora MA, Stufflebeam SM, Hämäläinen M, Moore CI (2009) Quantitative analysis and biophysically realistic neural modeling of the MEG mu rhythm: rhythmogenesis and modulation of sensory-evoked responses. J Neurophysiol 102:3554-3572. CrossRef Medline

Jones SR, Kerr CE, Wan Q, Pritchett DL, Hämäläinen M, Moore CI (2010) Cued spatial attention drives functionally relevant modulation of the mu rhythm in primary somatosensory cortex. J Neurosci 30:13760-13765. CrossRef Medline

Jovicich J, Czanner S, Greve D, Haley E, van der Kouwe A, Gollub R, Kennedy D, Schmitt F, Brown G, Macfall J, Fischl B, Dale A (2006) Reliability in multi-site structural MRI studies: effects of gradient non-linearity correction on phantom and human data. Neuroimage 30:436-443. CrossRef Medline

Kerr CE, Jones SR, Wan Q, Pritchett DL, Wasserman RH, Wexler A, Villanueva JJ, Shaw JR, Lazar SW, Kaptchuk TJ, Littenberg R, Hamalainen MS, Moore CI (2011) Effects of mindfulness meditation training on anticipatory alpha modulation in primary somatosensory cortex. Brain Res Bull 85:96-103. CrossRef Medline

Kerr CE, Sacchet MD, Lazar SW, Moore CI, Jones SR (2013) Mindfulness starts with the body: somatosensory attention and cortical alpha modulation in mindfulness mediation. Front Hum Neurosci 12:1-15. CrossRef Medline

Klimesch W (2012) Alpha-band oscillations, attention, and controlled access to stored information. Trends Cogn Sci 16:606-617. CrossRef Medline 
Klimesch W, Sauseng P, Hanslmayr S (2007) EEG alpha oscillations: the inhibition-timing hypothesis. Brain Res Rev 53:63-88. CrossRef Medline

Kühn AA, Williams D, Kupsch A, Limousin P, Hariz M, Schneider GH, Yarrow K, Brown P (2004) Event-related beta desynchronization in human subthalamic nucleus correlates with motor performance. Brain 127: 735-746. CrossRef Medline

Kveraga K, Ghuman AS, Kassam KS, Aminoff EA, Hämäläinen MS, Chaumon M, Bar M (2011) Early onset of neural synchronization in the contextual associations network. Proc Natl Acad Sci U S A 108:3389-3394. CrossRef Medline

Lachaux JP, Rodriguez E, Martinerie J, Varela FJ (1999) Measuring phase synchrony in brain signals. Hum Brain Mapp 8:194-208. CrossRef Medline

Leek MR (2001) Adaptive procedures in psychophysical research. Percept Psychophys 63:1279-1292. CrossRef Medline

Leventhal DK, Gage GJ, Schmidt R, Pettibone JR, Case AC, Berke JD (2012) Basal ganglia beta oscillations accompany cue utilization. Neuron 73:523536. CrossRef Medline

Levy BJ, Wagner AD (2011) Cognitive control and right ventrolateral prefrontal cortex: reflexive reorienting, motor inhibition, and action updating. Ann N Y Acad Sci 1224:40-62. CrossRef Medline

Lin FH, Belliveau JW, Dale AM, Hämäläinen MS (2006) Distributed current estimates using cortical orientation constraints. Hum Brain Mapp 27:1-13. CrossRef Medline

Liu AK, Dale AM, Belliveau JW (2002) Monte Carlo simulation studies of EEG and MEG localization accuracy. Hum Brain Mapp 16:47-62. CrossRef Medline

Miller KJ, Hermes D, Honey CJ, Hebb AO, Ramsey NF, Knight RT, Ojemann JG, Fetz EE (2012) Human motor cortical activity is selectively phaseentrained on underlying rhythms. PLoS Comput Biol 8:e1002655. CrossRef Medline

Mosher JC, Leahy RM, Lewis PS (1999) EEG and MEG: forward solutions for inverse methods. IEEE Trans Biomed Eng 46:245-259. CrossRef Medline

Nakamura A, Yamada T, Goto A, Kato T, Ito K, Abe Y, Kachi T, Kakigi R (1998) Somatosensory homunculus as drawn by MEG. Neuroimage 7:377-386. CrossRef Medline

Neubert FX, Mars RB, Buch ER, Olivier E, Rushworth MF (2010) Cortical and subcortical interactions during action reprogramming and their related white matter pathways. Proc Natl Acad Sci U S A 107:13240-13245. CrossRef Medline

Nolte G, Bai O, Wheaton L, Mari Z, Vorbach S, Hallett M (2004) Identifying true brain interaction from EEG data using the imaginary part of coherency. Clin Neurophysiol 115:2292-2307. CrossRef Medline

Sadaghiani S, Scheeringa R, Lehongre K, Morillon B, Giraud AL, D’Esposito M, Kleinschmidt A (2012) Alpha-band phase synchrony is related to activity in the fronto-parietal adaptive control network. J Neurosci 32: 14305-14310. CrossRef Medline

Sakai K, Passingham RE (2003) Prefrontal interactions reflect future task operations. Nat Neurosci 6:75-81. CrossRef Medline

Sauseng P, Klimesch W, Stadler W, Schabus M, Doppelmayr M, Hanslmayr S, Gruber WR, Birbaumer N (2005) A shift of visual spatial attention is selectively associated with human EEG alpha activity. Eru J Neurosci 22:2917-2926. CrossRef Medline

Schmiedt JT, Maier A, Fries P, Saunders RC, Leopold DA, Schmid MC (2014) Beta oscillation dynamics in extrastriate cortex after removal of primary visual cortex. J Neurosci 34:11857-11864. CrossRef Medline

Schroeder CE, Lakatos P (2009) Low-frequency neuronal oscillations as in- struments of sensory selection. Trends Neurosci 32:9-18. CrossRef Medline

Sharp DJ, Bonnelle V, De Boissezon X, Beckmann CF, James SG, Patel MC, Mehta MA (2010) Distinct frontal systems for response inhibition, attentional capture, and error processing. Proc Natl Acad Sci U S A 107: 6106-6111. CrossRef Medline

Siegel M, Donner TH, Oostenveld R, Fries P, Engel AK (2008) Neuronal synchronization along the dorsal visual pathway reflects the focus of spatial attention. Neuron 60:709-719. CrossRef Medline

Siegel M, Donner TH, Engel AK (2012) Spectral fingerprints of large-scale neuronal interactions. Net Rev Neurosci 13:120-134. CrossRef Medline

Swann N, Poizner H, Houser M, Gould S, Greenhouse I, Cai W, Strunk J, George J, Aron AR (2011) Deep brain stimulation of the subthalamic nucleus alters the cortical profile of response inhibition in the beta frequency band: a scalp EEG study in Parkinson's disease. J Neurosci 31: 5721-5729. CrossRef Medline

Swann NC, Cai W, Conner CR, Pieters TA, Claffey MP, George JS, Aron AR, Tandon N (2012) Roles for the pre-supplementary motor area and the right inferior frontal gyrus in stopping action: electrophysiological responses and functional and structural connectivity. Neuroimage 59: 2860-2870. CrossRef Medline

Swann N, Tandon N, Canolty R, Ellmore TM, McEvoy LK, Dreyer S, DiSano M, Aron AR (2009) Intracranial EEG reveals a time- and frequencyspecific role for the right inferior frontal gyrus and primary motor cortex in stopping initiated responses. J Neurosci 29:12675-12685. CrossRef Medline

Taulu S, Simola J, Kajola M (2005) Applications of the signal space separation method IEEE Trans Signal Process 53:3359-3372.

Tiihonen J, Kajola M, Hari R (1989) Magnetic mu rhythm in man. Neuroscience 32:793-800. CrossRef Medline

van Ede F, de Lange FP, Maris E (2012) Attentional cues affect accuracy and reaction time via different cognitive and neural processes. J Neurosci 32:10408-10412. CrossRef Medline

Wan Q, Kerr C, Pritchett D, Hämäläinen M, Moore C, Jones S (2011) Dynamics of dynamics within a single data acquisition session: variation in neocortical alpha oscillations in human MEG. PLoS One 6:e24941. CrossRef Medline

Weissman DH, Prado J (2012) Heightened activity in a key region of the ventral attention network is linked to reduced activity in a key region of the dorsal attention network during unexpected shifts of covert visual spatial attention. Neuroimage 61:798-804. CrossRef Medline

Wessel JR, Conner CR, Aron AR, Tandon N (2013) Chronometric electrical stimulation of right inferior frontal cortex increases motor braking. J Neurosci 33:19611-19619. CrossRef Medline

Womelsdorf T, Ardid S, Everling S, Valiante TA (2014) Burst firing synchronizes prefrontal and anterior cingulate cortex during attentional control. Curr Biol 24:2613-2621. CrossRef Medline

Worden MS, Foxe JJ, Wang N, Simpson GV (2000) Anticipatory biasing of visuospatial attention indexed by retinotopically specific alpha-band electroencephalography increases over occipital cortex. J Neurosci 20:1-6. Medline

Zanto TP, Rubens MT, Thangavel A, Gazzaley A (2011) Causal role of the prefrontal cortex in top-down modulation of visual processing and working memory. Nat Neurosci 14:656-661. CrossRef Medline

Ziegler DA, Pritchett DL, Hosseini-Varnamkhasti P, Corkin S, Hämäläinen M, Moore CI, Jones SR (2010) Transformations in oscillatory activity and evoked responses in primary somatosensory cortex in middle age: a combined computational neural modeling and MEG study. Neuroimage 52:897-912. CrossRef Medline 